images using an autostereoscopic screen - experimental study. BMC Ophthalmol 2008; 8: 13.

\section{SA Rizvi}

Department of Ophthalmology, Baqai Medical

University, Karachi, Sindh, Pakistan

E-mail: samjadhr@gmail.com

Eye (2009) 23, 242-243; doi:10.1038/eye.2008.353;

published online 21 November 2008

Supplementary Information accompanies the paper on Eye website (http://www.nature.com/eye)

\section{Sir, \\ Exploring glaucoma awareness and the utilization of primary eye care services: community perceived barriers among elderly African Caribbeans in Chapeltown, Leeds}

We read with interest the recent report of the ReGAE 2 study by $\mathrm{V}$ Cross $e t a l^{1}$ which closely matched the findings of a community-based qualitative study among the black African-Caribbean population in Chapeltown, Leeds, which we undertook in 2006 as fulfilment of a Masters in Public Health dissertation.

Our study was undertaken to explore knowledge and attitudes concerning glaucoma and investigated the utilization and barriers to uptake of primary eye care services (PECS). Although otherwise similar to the ReGAE 2 study in methodology and ethnic mix of participants, we took a purposive sample of the older population, median age of 75 compared to a median age of 42 in the ReGAE 2 report. Individual face to face semistructured transcribed interviews were conducted with 16 respondents and despite the demographic difference, many similarities in results were identified.

The utilization of PECS was largely symptom driven in both studies; however, in our older population, once a pattern of optometrist attendance had been established, receipt of optometrist letters advising repeat testing was reported as a substantial incentive for continued attendance (8/16). Family members were again reported as the most important source of information about glaucoma, although 14/16 (87\%) had heard of glaucoma compared to $67 \%$ in the ReGAE 2 study.

Barriers to utilization of PECS identified were very similar in both studies. Perceived cost of eye tests (despite all our participants being over 60 years old and therefore entitled to free testing) (6/16), mistrust of PECS $5 / 16$, fear of being pressurised to purchase expensive glasses $6 / 16$, were all disappointingly prevalent in this older population. Only three of the 16 respondents knew they could get free sight tests.

Another additional important barrier to utilization of PECS for the community in Leeds was the lack of optometrist in the Chapeltown area. Mapping of PECS in Leeds and comparison with socio-economic status (equity profile) revealed an unsurprising but important mismatch.

Initiatives to overcome attitudinal barriers to uptake of PECS are necessary both from the service user and the provider perspective. Accessibility of PECS in AfricanCaribbean and socio-economically deprived communities must also be addressed, possibly by community or health centre-based PECS provision. This would simultaneously address many of the 'fear-based' barriers as well as perceived transport difficulties for elderly populations needing to travel to more affluent areas to access a service they poorly understand the need for.

\section{Reference}

1 Cross A, Shah P, Bativala R, Spurgeon P. RagAE 2: glaucoma awareness and the primary eye care services; some perceptions among African Caribbeans in Birmingham, UK. Eye 2007; 21: 912-920.

JF Awobem¹, A Cassels-Brown², JC Buchan³ and KA Hughes ${ }^{4}$

${ }^{1}$ Hull and East Yorkshire Eye Hospital, East

Yorkshire, UK

${ }^{2}$ Department of Ophthalmology, St James's

University Hospital, Leeds, UK

${ }^{3}$ Bradford Royal Infirmary, Bradford, UK

${ }^{4}$ School of Sociology and Social Policy, University

of Leeds, Leeds, UK

E-mail: Andy.Cassels-Brown@leedsth.nhs.uk

Eye (2009) 23, 243; doi:10.1038/eye.2008.42;

published online 14 March 2008

Sir,

Response to Awobem et al

We thank the respondents for their helpful discussion concerning Cross et al. ${ }^{1}$ We fully endorse all their comments regarding the need to optimise utilisation of primary eye-care services by the community they serve. In our paper, we focused on the problems perceived and experienced by younger members of the African Caribbean community in an area of profound social deprivation in inner city Birmingham. The key to early glaucoma detection is to set up a community-based case-finding system, accessible and acceptable to the entire local community, which takes proper account of the need for culturally sensitive service delivery. There is a high prevalence of blinding disease in young African-Caribbeans, and the system must be responsive to the particular needs of this young working constituency.

\section{Reference}

1 Cross V, Shah P, Bativala R, Spurgeon P. ReGAE 2: glaucoma awareness and the primary eye-care service: some perceptions among African-Caribbeans in Birmingham UK. Eye 2007; 21: 912-920.

P shah and $V$ Cross

University of Wolverhampton, UK E-mail: vinette.cross@wlv.ac.uk

Eye (2009) 23, 243; doi:10.1038/eye.2008.43; published online 29 February 2008 